\title{
INTERPRETAÇÃO DE CONFERÊNCIAS: PERCEPÇÃO DE INTÉRPRETES DE LIBRAS-PORTUGUÊS SOBRE A ATUAÇÃO EM CABINE
}

Tiago Coimbra Nogueira ${ }^{1}$

${ }_{1}^{1}$ Universidade Federal do Rio Grande do Sul, Porto Alegre, Rio Grande do Sul,

Resumo: Neste trabalho, discutimos a interpretação das línguas de sinais, mais especificamente da Libras (Língua Brasileira de Sinais) para a Língua Portuguesa, em contexto de conferência na cabine. A princípio, abordamos o caminho da atuação dos intérpretes de conferência. Para isso, apresentamos um breve histórico contemplando alguns fatos presentes na literatura que destacam situações de interpretação em cabine e citamos alguns dos personagens históricos, a partir de Bowen et al. e Pagura. Em seguida, abordamos a interpretação em cabine realizada por intérpretes de línguas de sinais, na tentativa de descrever essa situação de interpretação, ainda rara para os intérpretes de língua de sinais no Brasil. Por fim, refletimos sobre as vantagens, problemas e desafios desse tipo de interpretação, com o intuito de apresentar uma discussão das percepções dos intérpretes e demonstrar pontos relevantes dessa realidade, pouco explorada por intérpretes de língua de sinais.

Palavras chave: Interpretação de conferência; Interpretação simultânea; Cabine de interpretação

\section{CONFERENCE INTERPRETATION: PERCEPTION OF LIBRAS-PORTUGUESE INTERPRETERS ABOUT THE PERFORMANCE IN THE BOOTH}

\begin{abstract}
In this paper, we argue about sign languages interpreting, especially about Libras (Brazilian Sign Language) to Portuguese, in the context of a conference on interpretation booth. Firstly, we will focus
\end{abstract}


on the work path of the interpreters in conference. For this purpose, we present a brief history showing some facts on the literature that highlight booth interpretation working situations and we quote some of the historical characters from Bowen et al. and Pagura. Then, we will discuss the booth interpreting performed by sign language interpreters, trying to describe this interpretation work situation, still unusual for sign language interpreters in Brazil. Finally, we think through the advantages, problems and challenges experienced, in order to present a discussion of perceptions and demonstrate main points of this work situation underexplored by sign language interpreters.

Keywords: Conference interpreting; Simultaneous interpreting; interpreting booth

\section{Introdução}

Neste trabalho, discutimos a interpretação de língua de sinais em conferências, mais especificamente da Libras (Língua Brasileira de Sinais) para Língua Portuguesa, realizada em cabine. O contexto de conferência envolve características múltiplas, relacionadas ao tipo de discurso e a configuração dos participantes, exigindo do profissional intérprete o amplo conhecimento de tais características.

Inicialmente, é necessário contextualizar que a interpretação de conferência ocorre em situações de alto nível e como conceito está relacionada à atuação em "palestras, transmissões de televisão ou reuniões de cúpula" (Shuttleworth and Cowie 26). Sendo assim, as conferências assumem outros formatos e frequentemente são espaços em que um locutor fala na direção de muitos interlocutores.

Abordamos neste texto o caminho da atuação dos intérpretes de conferência, para isso, apresentamos um breve histórico tematizando acontecimentos expressos na bibliografia que contemplam situações de interpretação em conferência, tanto de línguas orais, quanto de línguas de sinais. Além disso, citamos alguns personagens marcados historicamente, nos apoiando nos relatos descritos por Bowen et al. e Pagura. Também, discutimos sobre a interpretação em cabine realizada por intérpretes de línguas de sinais, com interesse em caracterizar essa situação de interpretação, pouco fre-

Cad. Trad., Florianópolis, v. 41, $\mathbf{n}^{0}$ esp. 2, p. 128-162, ago/dez, 2021.129 
quente no Brasil para os intérpretes de língua de sinais, conforme discutido por Nogueira (30).

Nessa perspectiva histórica, vale questionar quais são os benefícios de interpretar em cabine num evento em que a língua de sinais é a língua oficial? Assim, pretende-se abordar esse tema, a partir da percepção de intérpretes de Libras/Português que atuam em cabine, na interpretação simultânea realizada da língua de sinais para a língua oral. Tal abordagem tem interesse em discutir as vantagens, problemas e desafios percebidos pelos intérpretes, demonstrando pontos relevantes dessa realidade pouco explorada por intérpretes de língua de sinais.

\section{A interpretação de conferência em cabine: aspectos históricos}

Na história da humanidade, a tarefa de diluir obstáculos nas interações comunicativas orais é competência atribuída aos intérpretes, no entanto, em virtude da ausência de registros, contar a história dos intérpretes não é tarefa fácil. Algumas fontes auxiliam nesse processo de registro histórico: “[C]artas, diários, memórias, e bibliografias dos próprios intérpretes, assim como de uma variedade de outros documentos, muitos dos quais só de forma marginal ou incidentalmente relacionados com a interpretação" (Bowen et al. 257).

De acordo com Kurz, a evidência mais antiga sobre a ${ }^{1}$ atuação de intérpretes é coletada das inscrições encontradas nos túmulos dos príncipes de Elefantina, no Antigo Egito, que datam do terceiro milênio a.C. (Kurz qtd. in Luciano 9). Nos textos do historiador Heródoto, há uma referência - de aproximadamente 485-425 a.C. - aos intérpretes, na qual são chamados de hermeneutas ${ }^{2}$, palavra

\footnotetext{
${ }^{1}$ Língua oficial aqui quer dizer que preferencialmente essa é a língua de interação do evento, nas palestras e comunicações apresentadas.

${ }^{2}$ Hermeneutas em grego antigo significa “interpretar”.
}

Cad. Trad., Florianópolis, v. 41, $\mathrm{n}^{0}$ esp. 2, p. 128-162, ago/dez, 2021. 130 
relacionado ao deus Hermes, mensageiro da palavra dos deuses para os mortais (Bertoni qtd. in Luciano).

Assim, "no passado os intérpretes foram não só testemunhas da história, mas participaram no seu desdobramento" (Bowen et al. 257). Os intérpretes tinham uma posição marginal, portanto, poucos foram reconhecidos e contaram suas experiências, o que se explica pela posição social que ocupavam. Pagura (b 10) pontua que a função era comumente exercida por "híbridos culturais", que normalmente eram escravos ou membros de "subcastas" como cristãos, armênios e judeus, dispersos e, em sua maioria, do sexo feminino.

$\mathrm{Na}$ Idade Média, a "necessidade de usar intérpretes cresceu e foi reconhecida, por exemplo, os cronistas franceses se referiam aos intérpretes durante as cruzadas" (Bowen et al. 259).

Dois fatores fundamentais para que a interpretação se tornasse mais comum e que as menções a essa atuação fossem mais explícitas foram: a criação das nações europeias e o desenvolvimento das línguas nacionais. Nesse momento, em conferências em línguas orais prevalecia a interpretação feita de modo consecutivo. Esse tipo de interpretação acontece quando o intérprete ouve um trecho do discurso com a possibilidade de realizar alguma anotação nesse tempo e, após o término da produção na língua de partida, o intérprete assume o turno e realiza a produção na língua de chegada. (Nogueira, 67)

Bowen et al. e Pagura (b) afirmam que o melhor momento da interpretação consecutiva aconteceu na Conferência da Paz - em Paris, em 1919 - com acordos relacionados à Primeira Guerra Mundial e também em reuniões da Liga das Nações. Nesse período, a interpretação consecutiva foi sendo aperfeiçoada conforme as negociações internacionais eram realizadas. Bowen et al. apresentam as impressões do escritor e diplomata Salvador Mandariaga sobre os intérpretes:

Salvador de Madariaga (1886-1978), [...] menciona com admiração uma certa Madame Angeli, que podia "ouvir todo um discurso em inglês, francês ou italiano e repeti-lo sem jamais tomar uma só nota”. Madariaga comenta que

Cad. Trad., Florianópolis, v. 41, $\mathbf{n}^{0}$ esp. 2, p. 128-162, ago/dez, 2021. 131 
os intérpretes com essa habilidade se prestavam mais ao trabalho da Assembleia, enquanto outros, mais afeitos aos pronunciamentos curtos e aos comentários rápidos, se adaptavam melhor às comissões e, "quando dotados de tato e sensibilidade política”, ao Conselho. (260)

Com esse relato podemos perceber as capacidades e as habilidades distintas que eram exigidas desses profissionais, sendo possível identificar perfis diferentes de intérpretes e locais distintos de atuação. Uma outra situação, relatada por Bowen et al., ocorreu em 1898 na Conferência da Paz, quando os profissionais interpretaram frase por frase, para que o texto pudesse ser submetido à aprovação.

Diante dos fatos, é possível identificar demandas e posturas distintas que foram adotadas de acordo com o período e o contexto em que os intérpretes estavam inseridos. Naquele momento histórico a interpretação consecutiva dominava as atuações em conferências, no entanto essa estratégia passou a ser criticada, julgando-a incômoda quando envolve mais de duas línguas e, principalmente, pelo tempo que era demandado.

Em busca de novas soluções para aperfeiçoar a interpretação, Bowen et al. descrevem que a International Business Machine (IBM) - representada por Edward Filenes, Gordon Finlay e Thomas Watson - desenvolveu um equipamento que funcionava mediante o uso de microfones e fones de ouvidos, permitindo ao intérprete falar ao mesmo tempo em que o discurso a ser interpretado fora proferido. Em 1927, o sistema criado pela IBM foi usado pela primeira vez em contexto formal de conferência.

$\mathrm{Na}$ interpretação simultânea "a mensagem vai sendo reproduzida pelo intérprete conforme o orador emite o discurso, normalmente se produz com uma demora de poucos segundos" (Nogueira (a) 69). Por isso, é importante esclarecer que há necessidade do apoio da tecnologia na interpretação de línguas orais, como recurso que possibilita com que não ocorra sobreposição das línguas.

Bowen et al. postula que apesar das iniciativas anteriores, foi somente no ano de 1944 na Filadélfia quando o equipamento vol-

Cad. Trad., Florianópolis, v. 41, $\mathbf{n}^{0}$ esp. 2, p. 128-162, ago/dez, 2021.132 
tou a ser usado em uma conferência internacional. No entanto, as condições para a atuação não eram as melhores, uma vez que "os intérpretes ficaram no subsolo, embaixo do palanque dos oradores, e o ruído dos passos sobre a plataforma, combinado com a inadequação do equipamento, fabricado vinte anos atrás, dificultava o seu trabalho" (Roditi 10).

Mesmo diante desses diversos cenários, o principal destaque para a interpretação simultânea não ocorre em uma conferência internacional, mas no julgamento de criminosos nazistas de $\mathrm{Nu}$ remberg, entre novembro de 1945 e outubro de 1946. Pagura (b) relata que essa experiência:

[F]oi um julgamento totalmente peculiar, com muitas semelhanças a uma conferência internacional, uma vez que os juízes, promotores e seus assistentes falavam inglês, francês ou russo, enquanto os réus e grande parte de seus advogados de defesa falavam alemão. Como o sistema jurídico que vigorou foi o anglo-saxão, mais particularmente o dos Estados Unidos, os depoimentos e a chamada "crossexamination" pelos promotores impediam, por si só, o emprego da consecutiva. Na "cross-examination", a velocidade das perguntas e respostas tem um papel tão fundamental que os promotores reclamavam até mesmo da "lentidão" da simultânea. Além disso, a consecutiva num evento que incluía quatro idiomas prolongaria imensamente a sua duração. (46)

As quatro línguas utilizadas no julgamento foram o alemão, o francês, o inglês e o russo. Pagura (b) explica que a escolha da interpretação simultânea não se tratou de uma escolha tranquila e natural, surgiu, contudo, da total necessidade. A IBM emprestou o equipamento de forma gratuita, em vista da grande propaganda realizada pela utilização (Pagura (a)). Uma vez que, a realização da interpretação consecutiva de todo o julgamento "dificultaria a mecânica da atuação de testemunhas, promotores, advogados, juízes

Cad. Trad., Florianópolis, v. 41, $\mathbf{n}^{0}$ esp. 2, p. 128-162, ago/dez, 2021.133 
e réus" (Pagura (b) 46), tratando-se de uma situação complicada e de longa duração das sessões dos julgamentos.

Segundo as afirmações de Bowen et al. e Pagura (a), o responsável pelo serviço de interpretação em Nuremberg foi o coronel Léon Dostert (1904-71). O coronel selecionou intérpretes entre estudantes e professores da Universidade de Genebra, além de outras pessoas que possuíam competência linguística e experiência com a interpretação consecutiva. De forma geral, os intérpretes foram se aperfeiçoando com a prática, alguns trabalharam primeiro na seção de tradução para se acostumarem com os procedimentos e o vocabulário (Pagura (b)).

Enquanto coordenador dos trabalhos, Dostert foi quem organizou o cenário para que os intérpretes simultâneos não ficassem mais escondidos, como havia acontecido em 1927. Os intérpretes, em Nuremberg, foram alocados no fundo do salão em cabines de vidro abertas. Pagura (b) relata acerca da compreensão para tal finalidade, na realização da interpretação simultânea, descrevendo:

\begin{abstract}
Dostert quem insistiu na importância de os intérpretes serem colocados de maneira a ver o que acontecia no recinto para poderem ter a compreensão global do que se passava princípio básico do processo da interpretação simultânea, em que os intérpretes continuam a insistir hoje em dia, uma vez que dependem das expressões faciais e outros movimentos corporais tanto quanto das próprias palavras sendo proferidas, para terem uma compreensão global do sentido da mensagem. (47)
\end{abstract}

Nessa perspectiva, não só a palavra, mas os elementos corporais e faciais que combinados se tornaram indispensáveis para a compreensão do discurso que foi interpretado, já que os aspectos visuais complementam a fala e contribuem com a interpretação. Abaixo as figuras 1, 2 e 3 apresentam o local em que a equipe de intérpretes estava alocada.

Cad. Trad., Florianópolis, v. 41, $\mathrm{n}^{0}$ esp. 2, p. 128-162, ago/dez, 2021. 134 
Figura 1 - Tribunal de Nuremberg.

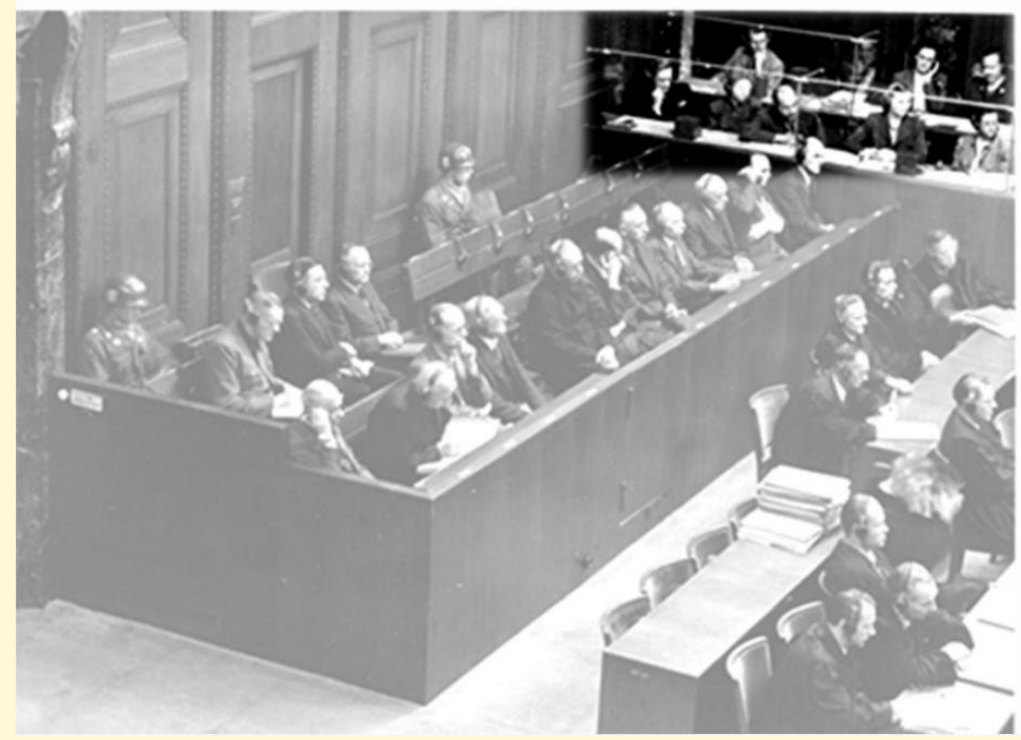

Fonte: Enciclopédia do Holocausto ${ }^{3}$.

${ }^{3}$ Os acusados no banco dos réus durante o julgamento, na parte superior da imagem tem o local onde as equipes de intérpretes ficavam. Disponível em: $<$ https://encyclopedia.ushmm.org/content/pt-br/photo/the-defendants-in-thedock-during-the-justice-case $>$. A foto foi manipulada a fim de dar destaque para o local onde os intérpretes atuavam.

Cad. Trad., Florianópolis, v. 41, $\mathrm{n}^{0}$ esp. 2, p. 128-162, ago/dez, 2021. 135 
Figura 2 - Intérpretes trabalhando.

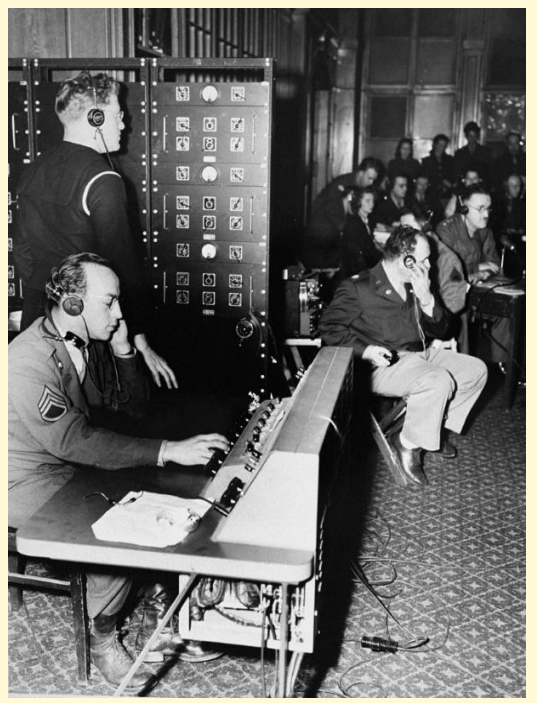

Fonte: Enciclopédia do Holocausto ${ }^{4}$

${ }^{4}$ Nesta foto, eles estão direcionando as interpretações por meio de um painel de controle aos participantes no julgamento. Nuremberg, Alemanha, novembro de 1945. Disponível em: < https://encyclopedia.ushmm.org/content/pt-br/photo/ translators-at-the-nuremberg-trial $>$.

Cad. Trad., Florianópolis, v. 41, $\mathrm{n}^{0}$ esp. 2, p. 128-162, ago/dez, 2021. 136 
Figura 3 - Vista da sala julgamento em Nuremberg.

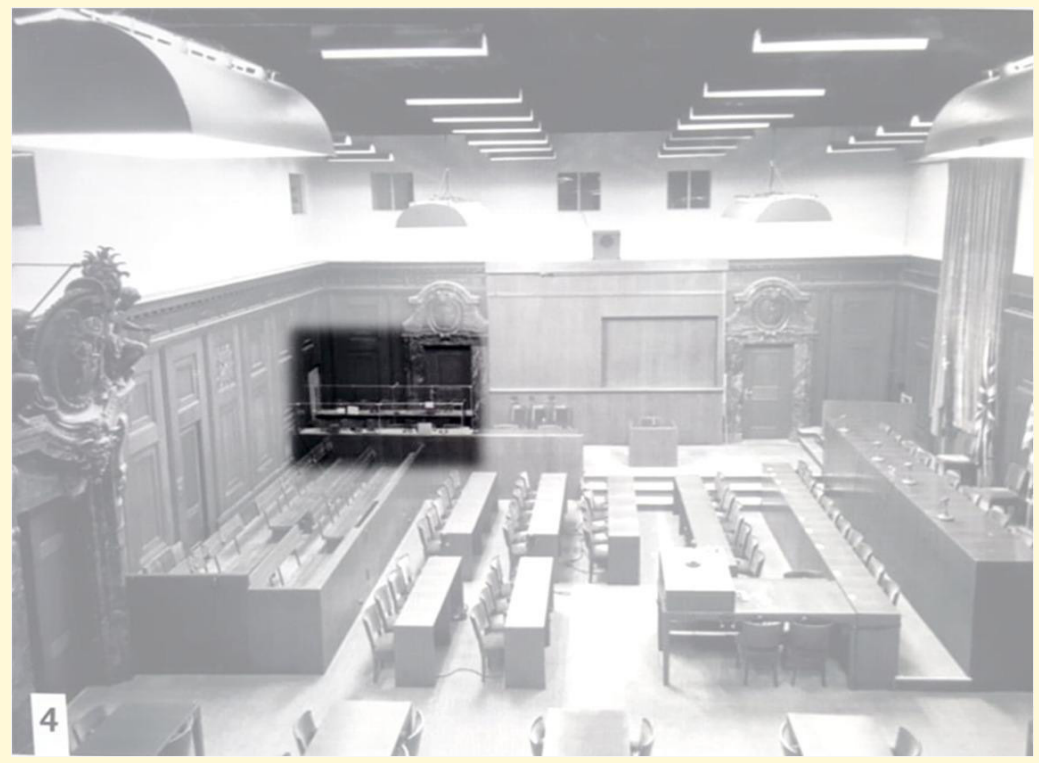

Fonte: acervo pessoal de Maitê Maus da Silva ${ }^{5}$

Pagura (b) (50) explica que em cada cabine atuavam três intérpretes, que dominavam a mesma língua de chegada. Na cabine do inglês, por exemplo, um intérprete trabalhava na direção do francês para o inglês, outro do russo para o inglês e outro do alemão para o inglês. A mesma organização era encontrada nas cabines de francês, russo e alemão.

A equipe geral do julgamento continha três subequipes, com um total de doze intérpretes cada. Enquanto uma atuava na sala do tribunal, outra ficava em uma sala ao lado, recebendo o som original e a interpretação dos colegas, para que estivessem prontos a substituí-los

5 Foto da sala onde ocorreu o julgamento de Nuremberg, retirada do Museu. Acervo pessoal de Maitê Maus da Silva que cedeu a fotografia para publicação nesse artigo.

Cad. Trad., Florianópolis, v. 41, $\mathrm{n}^{0}$ esp. 2, p. 128-162, ago/dez, 2021. 137 
quando necessário, enquanto a terceira equipe estava de folga para descansar (Pagura (b) 49). Nesse sentido, podemos dizer que havia um rodízio entre as três equipes: uma em atuação, uma de plantão caso ocorresse algum imprevisto e outra que estava em descanso.

A experiência do julgamento de Nuremberg fez com que a interpretação simultânea fosse conhecida e passasse a ser utilizada com mais frequência. Devido às experiências bem-sucedidas de interpretação o coronel Léon Dostert fora convidado para coordenar uma equipe de intérpretes que atuou nas Nações Unidas e que trabalhou com os seguintes idiomas: francês, russo, inglês e espanhol, além do chinês (Bowen). Porém, ainda havia certa resistência à implantação da modalidade de interpretação simultânea, uma vez que "a interpretação simultânea não era precisa e exata ao comparar com a consecutiva, ela obrigava todos a usarem fones de ouvido" (Pagura (b) 57) e que a consecutiva permitia aos delegados elaborarem melhor suas réplicas, segundo as concepções do contexto. Pois, nesse período de consolidação da interpretação simultânea,

Os poucos defensores da simultânea, sob a liderança de Dostert, apregoavam a enorme economia de tempo e, consequentemente, dinheiro que ela possibilita, além de permitir a utilização de todas as línguas oficiais da organização e uma reação mais rápida e natural durante os debates, sem privilegiar alguns delegados, uma vez que todos ouviriam o mesmo discurso ao mesmo tempo. Um argumento imbatível é que a simultânea estava sendo utilizada com êxito em Nuremberg. Parece claro, também, que havia grande preocupação por parte dos intérpretes consecutivos com uma possível perda de seu status de “estrelas". (Pagura (b) 57)

Assim, de forma gradativa a interpretação simultânea em cabine começou a ser implantada. Os comitês e organizações optaram por esse modelo em suas reuniões, pois, de fato, haviam muitas vantagens no uso desse tipo de interpretação, como a economia de tempo durante as sessões que deveriam ser interpretadas.

Cad. Trad., Florianópolis, v. 41, $\mathbf{n}^{0}$ esp. 2, p. 128-162, ago/dez, 2021.138 
A interpretação consecutiva e a simultânea continuavam sendo usadas nas assembleias gerais das Nações Unidas, no entanto, no ano de 1947, por intermédio da resolução 152, a "interpretação simultânea foi instituída como um serviço permanente em combinação com a consecutiva ou como uma alternativa" (Bowen 263). $\mathrm{O}$ autor ainda relata, em relação à consolidação da interpretação simultânea, que a partir de 1950, com o aprimoramento dos equipamentos, a modalidade passa a ser aceita integralmente e amplamente utilizada (Bowen).

Hoje, é praticamente inviável e impensável que em grandes eventos, com muitas línguas orais envolvidas, não se utilize a cabine para a realização da interpretação simultânea. Ela se tornou um elemento importante para a realização do evento e um recurso fundamental à produção da interpretação simultânea nas línguas orais. Em seguida descreveremos algumas características da cabine com a finalidade de orientar a posterior discussão.

\section{Características da cabine de interpretação simultânea}

os recursos técnicos e tecnológicos são um elemento importante para a realização da interpretação simultânea nas línguas orais. Nestas línguas, a cabine é utilizada para que não se tenha a sobreposição de vozes. Já que, os intérpretes se isolam em uma cabine à prova de som e recebem o áudio do palestrante por meio de fones de ouvido, à medida que ouvem o discurso na língua-fonte vão interpretando e produzindo o discurso na língua-alvo que, captada pelo microfone, é encaminhada ao público - por meio de ondas de rádio - com seus receptores sem fio e fones de ouvido individuais para que acessem a interpretação produzida na cabine.

A Associação Internacional de Intérpretes de Conferência (AIIC), orienta que as cabines, fixas ou móveis, devem seguir as normas de isolamento acústico, dimensões do espaço, qualidade do ar, acessibilidade e devem dispor de equipamento adequado, como fones de ouvido e os microfones que possibilitem a realização da

Cad. Trad., Florianópolis, v. 41, $\mathbf{n}^{0}$ esp. 2, p. 128-162, ago/dez, 2021.139 
interpretação sem interferências. As normas técnicas ISO 2603 e ISO 4043 (Directorate General for Interpretation web) descrevem as características que devem ser levadas em consideração para a realização da interpretação simultânea, para cabines fixas e móveis, três requisitos são essenciais:

\begin{abstract}
a. a separação acústica dos diferentes idiomas falados simultaneamente, de modo a evitar interferências recíprocas entre os idiomas interpretados ou com o orador da sala de conferência; b. permitir uma boa comunicação nos dois sentidos entre, por um lado, os intérpretes e os conferencistas e, por outro, entre as diversas cabines de interpretação; c. criar um ambiente de trabalho confortável que permita aos intérpretes manter os intensos níveis de concentração exigidos pelo seu trabalho (Directorate General for Interpretation web)
\end{abstract}

É preciso que a cabine tenha isolamento acústico a fim de evitar que a interpretação interfira na escuta da plateia, bem como, permitir que os intérpretes escutem com clareza o som do palestrante recebido em seus fones.

Outro aspecto imprescindível, como ocorreu em Nuremberg e ainda hoje, é a condição dos intérpretes visualizarem os oradores, já que aspectos de gestualidade refletem na mensagem transmitida. Além do mais, é comum aos palestrantes exibir apresentações e realizar referências, assim, uma escolha interpretativa mais adequada vai depender desses fatores. Nesse sentido conforme a norma ISO 2023 sobre a localização da cabine no auditório:

Deverão estar em local elevado para garantir uma ampla visão da sala (deverá haver janelas em toda a extensão das cabines). É extremamente importante que os intérpretes e o operador possam ver claramente os oradores, o presidente da mesa e todos os demais equipamentos visuais (telas de projeção, mapas, flipcharts, quadros, etc.) (Directorate General for Interpretation web)

Cad. Trad., Florianópolis, v. 41, $\mathrm{n}^{0}$ esp. 2, p. 128-162, ago/dez, 2021. 140 
Nesse sentido, vale mencionar que a interpretação em cabine de uma língua oral para uma língua de sinais não é necessária, haja vista as razões que são empenhadas nas línguas orais, já que é utilizada para evitar sobreposição das vozes. O que não ocorre quando a interpretação é realizada da língua de sinais para uma língua oral, assim as razões de se utilizar a cabine são de outras ordens.

Nascimento e Nogueira - em apresentação no congresso da Associação Brasileira de Tradutores e Intérpretes - ABRATES no ano de 2017 — , tratam sobre as semelhanças e diferenças na atuação de intérpretes de línguas de sinais e de línguas orais na cabine. Menciona-se o posicionamento dos intérpretes de Libras em conferências de duas formas: (a) uma quando a direção da interpretação é da Língua Portuguesa para a Libras, nessas situações o intérprete se encontra no palco (Figura 4); ou (b) quando a interpretação é realizada na direção da Libras para a língua portuguesa, nesses casos, antes do uso da cabine os intérpretes normalmente se localizavam nas primeiras cadeiras da primeira fileira do auditório, bem à frente do palestrante (Figura 5).

Figura 4 - Direção, Libras - Língua portuguesa.

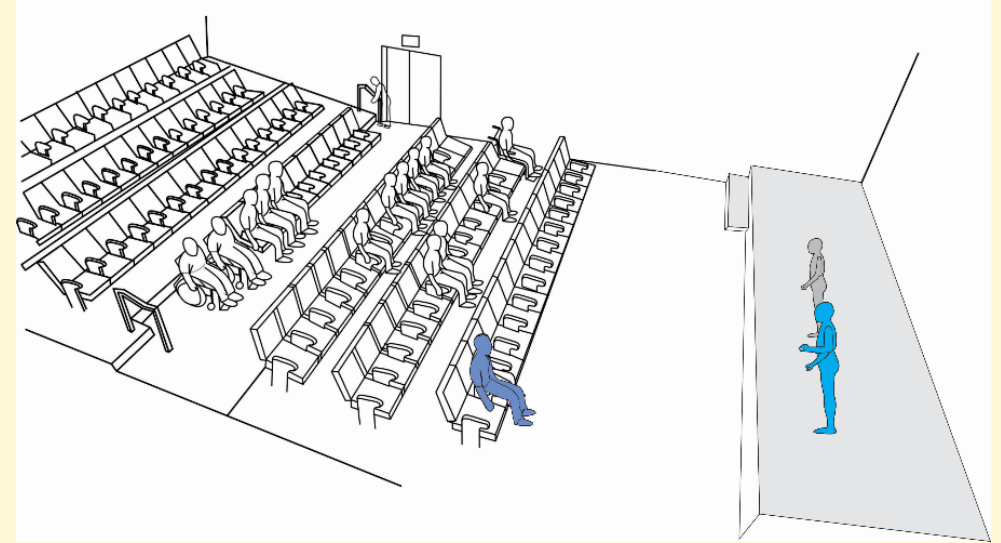

Fonte: Nascimento e Nogueira, 2017.

Cad. Trad., Florianópolis, v. 41, $\mathrm{n}^{0}$ esp. 2, p. 128-162, ago/dez, 2021. 141 
Figura 5 - Direção, Língua portuguesa - Libras.

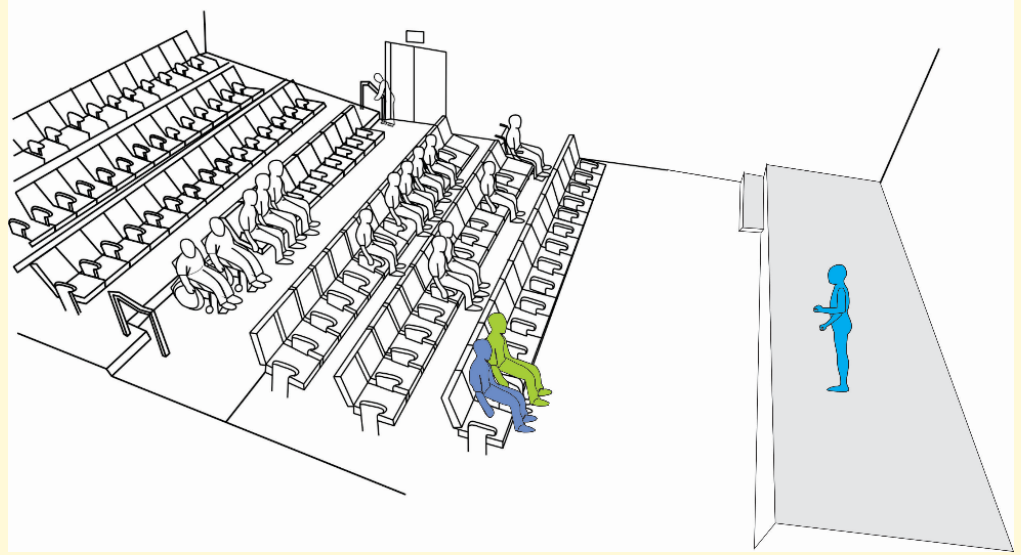

Fonte: Nascimento e Nogueira, 2017.

Quanto aos intérpretes de língua orais, o posicionamento frequente é na cabine, ao realizar a interpretação simultânea. No caso dos intérpretes de línguas de sinais localizam-se tanto no palco, quanto no auditório ou ainda na cabine, interpretando de forma consecutiva, observa-se que, no entanto, pela questão da direção da língua; e não necessariamente pela forma da interpretação consecutiva ou simultânea. Geralmente, os intérpretes de língua de sinais estão no palco e a interpretação continua sendo simultânea.

Quando os intérpretes que trabalham com uma língua de sinais estão posicionados em frente do auditório para realizar interpretação de Libras para português, normalmente usam o microfone e sua interpretação é escutada por todos os ouvintes daquele evento. Para o campo da interpretação de língua de sinais, o uso de cabines ainda está em desenvolvimento, já que se torna uma normalização da prática interpretativa, onde os intérpretes saem do palco ou da frente do auditório para a cabine.

Cad. Trad., Florianópolis, v. 41, $\mathrm{n}^{0}$ esp. 2, p. 128-162, ago/dez, 2021.142 
O Congresso Nacional de Pesquisas em Tradução e Interpretação de Língua de Sinais e Língua Portuguesa - Congresso TILS, no ano de 2014, foi a primeira edição do evento que tivemos conhecimento do uso da cabine para a interpretação da Libras para Português. A prática de atuação nesse evento por uma equipe de intérpretes é descrita na dissertação de Nogueira (a) intitulada: "Intérpretes de Libras-Português no contexto de conferência: Uma descrição do trabalho em equipe e as formas de apoio na cabine". Nessa ocasião, não haviam muitas referências a seguir e diante desse novo cenário, de atuação em cabine, todas as instruções eram baseadas a partir da investigação acerca da atuação em línguas orais, das impressões da equipe de organização, das hipóteses sobre o trabalho e na própria cena interpretativa em andamento.

No entanto, na abertura do evento os participantes perceberam que a interpretação ocorreria na cabine, era necessário recorrer aos fones de ouvido, e muitos procuram pelo equipamento.

\begin{abstract}
Eram em torno de 600 inscritos, foram disponibilizados inicialmente 250 equipamentos com fones de ouvido, a empresa contratada traz uma reserva de mais 100 dispositivos, que logo precisou ser disponibilizado. Após todos os 350 equipamentos já terem sido disponibilizados, a organização do evento procurou a empresa contratada, a qual forneceu mais 100 fones, totalizando 450 equipamentos, assim, consequentemente tínhamos, em média, 450 pessoas recorrendo à interpretação durante o evento (Nogueira (a) 172).
\end{abstract}

Inferimos que alguns fatores podem ter influenciado na procura - maior que a expectativa - pelo equipamento de interpretação, destacamos os dois mais relevantes: (I) a falta de hábito de participar de eventos exclusivamente em Libras, (II) a curiosidade pela novidade.

A adaptação necessária, para interpretação de uma língua de sinais, foi a inclusão de um monitor de LED de 32 polegadas na cabine. Esse monitor recebia a imagem do orador no palco captu- 
rada por uma câmera. Logo, a imagem recebida na cabine foi input da língua-fonte que precisava ser exibida com nitidez para a interpretação da língua-alvo. Após o evento de 2014, outros eventos nacionais optaram por usar a cabine em suas edições. Por exemplo, o Congresso Internacional do INES, no Rio de Janeiro, que ocorre anualmente e, desde a edição de 2015, disponibiliza a interpretação realizada em cabines. Também o I Congresso Internacional de Lexicologia, Lexicografia, Terminologia e Terminografia das Línguas de Sinais realizado no ano 2018, em Brasília. De forma que, também temos conhecimento de alguns eventos realizados no Itaú Cultural, em São Paulo, que optam pelo uso da cabine de interpretação simultânea.

Nascimento e Nogueira descrevem algumas semelhanças e diferenças da interpretação em cabine para intérpretes de línguas orais e intérpretes de língua de sinais. As semelhanças localizam-se no uso dos equipamentos, como: headset, central de controle e a atuação em dupla; e as diferenças apresentam-se na atuação a partir de uma língua de sinais com maior participação do concabino ${ }^{6}$, recepção do discurso pela visão e não pela audição, e uso de headset apenas para o microfone, já que a interpretação é realizada a partir da imagem que é exibida no monitor de vídeo.

Na norma técnica ISO 2023 um monitor já é previsto para os intérpretes de línguas orais quando o auditório é muito grande, tal recurso têm objetivos distintos diante dos intérpretes de língua de sinais, no entanto, é previsto para uso nas cabines. Assim,

É essencial que haja uma visão direta e ampla de todo o auditório, incluindo a tela de projeção. Para grandes auditórios poderão ser usados monitores de televisão para maior apoio visual. Os monitores deverão oferecer uma visualização adequada para minimizar o cansaço visual. Deve-se prestar atenção especial às distâncias monitor-inté-

6 "Concabino" é o termo usado na gíria da interpretação simultânea para designar o colega de cabine (Magalhães Junior).

Cad. Trad., Florianópolis, v. 41, $\mathrm{n}^{0}$ esp. 2, p. 128-162, ago/dez, 2021. 144 
rprete para que se evitem possíveis danos devido à radiação

(Directorate General for Interpretation web, grifo nosso).

Acreditamos que essas recomendações também se aplicam à prática dos intérpretes de língua de sinais, uma vez que o distanciamento do monitor-intérprete deve ser também considerado. Neste trabalho podemos compreender detalhadamente as percepções da equipe de intérpretes sobre a prática da interpretação em cabine. A seguir descrevemos os caminhos metodológicos empenhados no desenvolvimento da investigação.

\section{Procedimento metodológico}

O presente estudo é de caráter descritivo e exploratório, pretende observar e entender sobre a atuação em cabine de interpretação simultânea, a partir da realidade de intérpretes de Libras-Português. Para cumprirmos com o objetivo da pesquisa foi formulado um questionário a ser respondido de forma anônima e online, na ferramenta Google forms, com o interesse de identificar na fala de intérpretes com experiências em interpretação em cabine, observando os benefícios e desafios dessa atuação em um evento em que a língua de sinais é a língua oficial.

A construção do questionário envolveu os seguintes passos: (I) seleção e classificação dos itens a serem perguntados, este passo consiste em gerar itens para compor o questionário, a partir da revisão da literatura da área, no nosso caso se inspira nos dados apresentados por Nogueira em 2016; (II) busca a seleção da escala apropriada, este passo consiste em selecionar uma escala para as perguntas do questionário, que seja capaz de gerar tanto dados qualitativos, quanto dados quantitativos - opção por perguntas abertas em grande parte do questionário contribuiu para que mais dados qualitativos fossem gerados; (III) elaboração da versão final do questionário, que é submetida aos participantes da pesquisa. Abaixo apresentamos as perguntas do questionário:

Cad. Trad., Florianópolis, v. 41, $\mathbf{n}^{0}$ esp. 2, p. 128-162, ago/dez, 2021. 145 
1- Você já realizou interpretação simultânea em cabine? Sim ( ) Não ( )

2- Você se recorda de quantos eventos já interpretou na cabine?

[ ] Apenas 1 evento. [] 2 eventos. [ ]3 eventos. [ ] mais de 4 eventos. [ ] Não me recordo.

3- De forma geral, o que você pensa sobre o uso da cabine de interpretação simultânea em congressos que a Língua de Sinais é a língua oficial?

4- Identifica alguma vantagem de interpretar na cabine e não diretamente no auditório? Justifique sua resposta.

5- Identifica algum problema, desvantagem ou desafio de interpretar na cabine e não diretamente no auditório? Justifique sua resposta.

6- Você encontra alguma dificuldade em operar os equipamentos da cabine? Microfone, botão de mute, televisor, e outros?

7- Você viveu alguma experiência que prejudicou sua atuação?

8- Em um evento, o que você acredita que pode ser feito para contribuir com a interpretação simultânea em cabine?

9- Percebe algo que prejudica a atuação na cabine? Se sim, comente sobre isso.

10- Dos sentimentos abaixo quais identificam mais a sua atuação em cabine?

[ ] Medo [ ] Insegurança [ ] Segurança [ ] Proteção [ ] Alívio [ ] Exposição [ ]Fragilidade [ ] Incerteza [ ] Liberdade [ ] Concentração.

Cad. Trad., Florianópolis, v. 41, $\mathrm{n}^{0}$ esp. 2, p. 128-162, ago/dez, 2021. 146 
Os participantes da pesquisa foram selecionados em razão da composição na equipe de dois eventos em que a língua oficial era a Libras, e que a interpretação havia ocorrido em cabine, a saber o Congresso Nacional de Pesquisas em Tradução e Interpretação de Libras e Língua Portuguesa e o Congresso Internacional de Lexicologia, Lexicografia, Terminologia e Terminografia das Línguas de Sinais. O questionário foi enviado para dois grupos no aplicativo WhatsApp, que reunia a equipe de intérpretes dos dois eventos. Os participantes que aceitassem participar deveriam responder a todas as perguntas, confirmando que possuíam experiência em interpretação em cabine e aceitando os termos de consentimento da pesquisa. O formulário ficou disponível entre 08 e 12 de junho de 2020 e todos foram informados que as respostas seriam registradas anonimamente. Contabilizamos onze intérpretes nas respostas ao questionário e foram nomeados de P1 a P11, conforme a ordem das respostas.

A análise realizada buscou, preferencialmente, as experiências compartilhadas pelos participantes, ou seja, situações comuns nas respostas. Pontos apresentados por apenas um dos participantes não serão alvo desta discussão.

\section{Resultados e discussão}

nesta sessão discutiremos os dados coletados, a partir das respostas dos participantes da pesquisa. A primeira pergunta buscou garantir que somente as pessoas que atuaram nos congressos selecionados respondessem ao questionário, evitando assim que o formulário pudesse ter sido direcionado para intérpretes que não atuaram nos eventos selecionados.

Das respostas recebidas, como esperávamos, todos os intérpretes informaram que tinham experiência com a atuação em cabine. Interessante é que na resposta à segunda pergunta - "Você se recorda de quantos eventos já interpretou na cabine?" - verifica-se que alguns haviam interpretado em cabine em mais de um evento,

Cad. Trad., Florianópolis, v. 41, $\mathrm{n}^{0}$ esp. 2, p. 128-162, ago/dez, 2021. 147 
o que demonstra a expansão dessa atuação, mesmo que ainda seja uma realidade pouco comum.

\section{Gráfico 1}

Quantos eventos já interpretou na cabine?

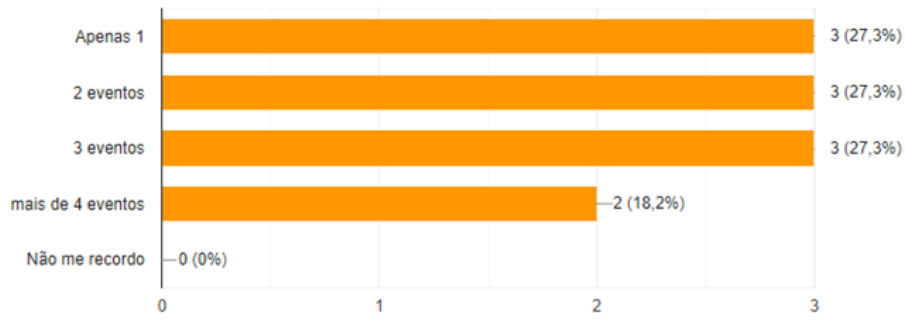

Fonte: arquivo do autor.

Na pergunta número três, o questionamento foi sobre o uso da cabine de interpretação simultânea em congressos nos quais a Língua de Sinais é a língua oficial. Sabe-se que o uso da cabine para a interpretação de uma língua de sinais para uma língua oral ocorre por motivos distintos da interpretação em cabine entre línguas orais. Nas respostas (conforme tabela 1), os participantes descreveram motivos para a atuação ocorrer em cabine sendo possível perceber duas vertentes, que aqui chamamos de categorias, $\left(1^{\circ}\right)$ relação ao público do evento e a outra $\left(2^{\circ}\right)$ em relação à própria equipe. 


\section{Tabela 1}

Motivos para o uso da cabine

\begin{tabular}{|l|l|}
\hline \multicolumn{1}{|c|}{ Categorias } & \multicolumn{1}{c|}{ Falas representativas } \\
\hline $\begin{array}{l}\text { Em relação ao } \\
\text { público do evento }\end{array}$ & $\begin{array}{l}\text { P1- "[...] pois possibilita aos participantes do evento que são fluentes na língua oficial } \\
\text { acompanhar o evento sem a interpretação, visto que não necessitam." } \\
\text { P4- "Garante aos participantes desses congressos o "conforto linguístico" em } \\
\text { acompanharem as conferências e palestras em sua língua de conforto." } \\
\text { P5- "Endossa a LS comolíngua oficial do evento." }\end{array}$ \\
\hline $\begin{array}{l}\text { Em relação a equipe } \\
\text { de intérpretes do } \\
\text { evento }\end{array}$ & $\begin{array}{l}\text { P2- "[..] melhor qualidade no trabalho da interpretação e apoio." } \\
\text { P3-...] um ambiente mais tranquilo pra deixar os materiais de estudo, pra focar na } \\
\text { tela em que está sendo reproduzindo o vídeo sinalizado, pra receber um apoio etc." } \\
\text { P6- "Uma sensação de segurança maior, bem como um apoio mais eficaz." }\end{array}$ \\
$\begin{array}{l}\text { P7- "proporciona maior conforto aos intérpretes, pois ela funciona como uma } \\
\text { proteção em relação ao público, principalmente quando parte deste conhece as } \\
\text { línguas de trabalho e pode acabar interferindo no momento da atuação." } \\
\text { P9- "maior foco por parte dos profissionais já que estão sujeitos a menos } \\
\text { interferência de fatores externos e tem mais possibilidades de usar ferramentas de } \\
\text { apoio à interpretação". } \\
\text { P10- "Mais segurança para o trabalho em equipe, logo melhor qualidade de } \\
\text { interpretação, visto que podemos trabalhar em um espaço com controles, matérias } \\
\text { de consulta, olhar para o colega, receber apoio de diferentes maneiras." }\end{array}$
\end{tabular}

Fonte: elaborado pelo autor. 2020

Sobre os pontos apresentados em relação ao público do evento, obtivemos justificativas pertinentes para o uso da cabine. Pois, quando a interpretação não é realizada nesse espaço, normalmente é feita de forma aberta, possibilitando às pessoas ouvintes-bilíngues escuta da interpretação. Com a cabine, esse público pode acompanhar a fala do palestrante sem a interferência e endossar a língua de sinais como língua oficial, isto é, o espaço linguístico da língua de sinais fica mais evidente, visto que a língua oral não está interferindo na atenção do público ouvinte-bilíngue.

Em relação à equipe de intérpretes do evento, alguns pontos interessantes foram citados como: maior qualidade na interpretação com apoio, proteção em relação ao público e menos interferência de fatores externos, além de possibilitar o uso de recursos externos tais como materiais de estudo pesquisados para a interpretação. Comentaremos mais sobre esses aspectos a seguir.

A tabela 2 apresenta respostas sobre as vantagens de interpretar na cabine, geradas a partir da pergunta número quatro sobre os ganhos em detrimento da interpretação diante do público.

Cad. Trad., Florianópolis, v. 41, n $^{0}$ esp. 2, p. 128-162, ago/dez, 2021.149 


\section{Tabela 2}

Vantagens de interpretar na cabine

\begin{tabular}{|c|c|}
\hline Categorias & Falas representativas \\
\hline $\begin{array}{l}\text { Apoio entre a } \\
\text { equipe }\end{array}$ & $\begin{array}{l}\text { P4- "Sem a interferência de ruídos que possam atrapalhar a interpretação; facilidade com o apoio;" } \\
\text { P5- "Privacidade para equipe de intérpretes." } \\
\text { P6- "As estratégias de apoio são bem mais amplas". } \\
\text { P7- "[...] O trabalho de apoio pode ser mais efetivo devido a menor exposição da equipe." } \\
\text { P8- "[..]privacidade e proteção, uma troca com o intérprete de apoio menos tensa em relação ao } \\
\text { público." } \\
\text { P11-“ [...] utilização de diversas formas de apoio [...] sem a interferência de ruídos que possam } \\
\text { atrapalhar a interpretação; facilidade com o apoio." }\end{array}$ \\
\hline $\begin{array}{l}\text { Fatores } \\
\text { emocionais }\end{array}$ & $\begin{array}{l}\text { P1- "Exposição reduzida." } \\
\text { P2- "Mas posso citar a vantagem do controle de demandas intrapessoais (questões emocionais), e } \\
\text { principalmente melhor recepção de apoio. Sem falar que o palestrante (tantos surdos quanto } \\
\text { ouvintes) pode palestrar à vontade, sem se preocupar ou ser influenciado pela interpretação." } \\
\text { P7- "[...] O intérprete está mais protegido[...] } \\
\text { P8- "[...] menos tensa em relação ao público". } \\
\text { P9-“O TILSP não fica exposto e atendendo apenas o público que necessita do serviço". } \\
\text { P11- Segurança [...] }\end{array}$ \\
\hline $\begin{array}{l}\text { Recursos } \\
\text { externos }\end{array}$ & $\begin{array}{l}\text { P7- "[...] Se todos os equipamentos estiverem funcionando adequadamente a concentração é bem } \\
\text { maior[...]." } \\
\text { P10- "O local reservado, a possibilidade de estar com computador ou celular para pesquisa rápida". } \\
\text { P11- "[...] recursos tecnológicos" }\end{array}$ \\
\hline
\end{tabular}

Fonte: elaborado pelo autor. 2020

Conforme as respostas aglutinadas na categoria "apoio entre a equipe" identificamos que, o trabalho na cabine possibilita aos intérpretes se apoiarem de forma mais efetiva. Essa é uma das características relevantes da interpretação simultânea, já que “a necessidade das equipes de intérpretes de trabalhar em conjunto é para garantir equivalência na mensagem na língua-alvo, isso requer que as equipes determinem quando e como fornecer apoios" (Hoza 6). Nesse sentido, o apoio é uma forma direta de intervenção para contribuir com o colega que está com o microfone ligado produzindo a interpretação para o público.

Esses apoios podem ser desde um aceno com a cabeça, indicações visuais que o intérprete do turno está no caminho certo, ou sugestões de palavras ou até mesmo conceitos. Por isso, é fundamental que os intérpretes discutam com antecedência formas que preferem receber apoios. Conforme Cokely e Hawkins em seu trabalho de 2013 a inclinação do corpo, olhar, silêncio, a expressa solicitação e toque no intérprete na função de apoio são compor-

Cad. Trad., Florianópolis, v. 41, $\mathrm{n}^{0}$ esp. 2, p. 128-162, ago/dez, 2021. 150 
tamentos adotados pelas equipes para solicitar apoio. Na pesquisa de Nogueira (a) (153) - que discute a atuação de equipes de intérpretes na cabine -, identifica-se que os intérpretes do turno inclinavam seu corpo para frente e olhavam para o concabino solicitando apoio. Nessa inclinação evidencia-se um comportamento que manifesta pedido direto de apoio.

Alguns intérpretes realizavam pausas ou ficavam alguns períodos em silêncio, nesse sentido, seria um indicativo da necessidade do apoio da equipe. Cokely e Hawkins (60) indicam que o silêncio poderia ser uma convocação para que o apoio atuasse. Nessa lógica, os autores problematizam a questão, pois o silêncio pode ser encarado como a ausência de comportamento, ao invés de um comportamento em si. Porém, o silêncio conteria uma ambiguidade na seguinte situação: o "silêncio poderia indicar que o intérprete do turno está processando o que está sendo dito ou que o intérprete do turno não compreendeu a mensagem no idioma de origem" (Cokely, Hawkins 60). Nogueira (a) (153) relata que "para eliminar a ambiguidade, caberia uma postura do intérprete do turno em avisar ao seu colega de cabine", tornando evidente a necessidade ou não de alguma intervenção.

Russel (5) aponta que "uma das chaves para o trabalho em equipe eficaz é a comunicação". Desse modo, a cabine parece ser um espaço mais tranquilo para que essas combinações aconteçam, reafirmando os enunciados que os intérpretes desse estudo registraram, segundo os participantes há um espaço de "privacidade para equipe", "uma troca com o intérprete de apoio menos tensa em relação ao público". Como a equipe não está em um local aberto e de visão do público podem mobilizar outras estratégias para se apoiarem.

Nogueira (a) (154-155) descreve que os intérpretes participantes de sua pesquisa usam gestos para comunicar a necessidade de apoio e também usavam o equipamento da cabine como forma de solicitar apoio:

Ele apertava o botão “off” do microfone e então com o áudio não mais disponível para o público ele solicitava o apoio ao seu colega. O sistema de microfone disponível dentro da

Cad. Trad., Florianópolis, v. 41, $\mathbf{n}^{0}$ esp. 2, p. 128-162, ago/dez, 2021. 151 
cabine permite que o intérprete, ao manter o botão pressionado, que o áudio captado pelo microfone seja cortado (Nogueira) (a) 158).

No estudo de Nogueira (a) (125) é possível encontrar a descrição de sete tipos de apoios que os intérpretes utilizam dentro da cabine e a descrição das formas como esses apoios foram oferecidos; o que autor chama no estudo de tipos de produção, são elas: "aceno com a cabeça, sussurro, sinal e soletração manual”. Com o sussurro esses tipos de produção para o oferecimento do apoio ocorrem com quatro formas linguísticas variadas, são elas: "por uma frase longa em língua portuguesa (FLP) - formada por quatro ou mais palavras - , uma frase curta em língua portuguesa (FCP) - com até três palavras - ou apenas uma palavra em língua portuguesa (1PP)" (Nogueira) (a) 125 grifo do autor).

Essas estratégias são formas eficientes para qualificar a interpretação e utilizar dos benefícios da atuação em equipe. Além do apoio, fatores emocionais são alguns aspectos, levantados pelos intérpretes, vantajosos no trabalho em cabine. Magalhães Junior (65) diz que o "grande limitador de rendimento na tradução simultânea é emocional, não linguístico". Logo, podemos inferir que se os intérpretes se sentem mais confiantes e menos expostos na cabine, podendo contribuir significativamente para a interpretação.

Esse fator diretamente ligado às questões emocionais, demonstra que os intérpretes se sentem menos preocupados com temores presentes na atuação fora da cabine. Como o nível de exposição dos intérpretes torna-se menor na cabine, os palestrantes surdos e ouvintes na mesma posição, mantém-se na mesma posição, uma vez que não há acesso ao monitoramento da atuação do intérprete. Observamos que essa é uma das vantagens nesse contexto.

Exigindo um alto grau de profissionalismo e competência tradutória - ou melhor interpretativa - da equipe de intérpretes na cabine, há um afastamento do controle do palestrante e das intervenções entre intérprete e palestrante. No entanto, quando os intérpretes participantes foram questionados sobre dificuldades da 
interpretação em cabine, alguns relataram sobre o distanciamento do emissor do discurso; conforme dados coletados a partir da pergunta 6 , apresentados na tabela 3 .

\title{
Tabela 3
}

\section{Dificuldades}

\begin{tabular}{|l|l|}
\hline & \multicolumn{1}{|c|}{ Falas representativas } \\
\hline $\begin{array}{l}\text { Dificuldade de ver o } \\
\text { locutor da palestra. "Falta de contato com o locutor surdo." }\end{array}$ & $\begin{array}{l}\text { P2- "Não! Mas ouço muito alguns colegas falando da falta de contato visual com o surdo, porém } \\
\text { eu discordol" } \\
\text { P7-“[...] Outra questão que pode ser considerada uma desvantagem em algumas situações é a } \\
\text { impossibilidade contato visual e de interação com o orador em língua de sinais." } \\
\text { P10- "A depender de como foi montada a estrutura, o retorno de vídeo do palestrante e dos slides } \\
\text { da apresentação podem não ser tão claros." }\end{array}$ \\
\end{tabular}

Fonte: Criado pelo autor

Ao refletir sobre tal condição, quando os intérpretes estão posicionados no auditório - em frente ao palestrante - as elucidações que o intérprete do turno necessita são, muitas vezes, direcionadas ao palestrante, interrompendo diretamente a palestra. Em relação ao contexto

\begin{abstract}
[É] interessante notar que a cabine parece quebrar com essa relação palestrante-intérprete. Em muitos eventos que participamos em que os intérpretes não estão na cabine e realizam a interpretação no auditório, é comum notarmos palestrantes proferindo sua conferência para os intérpretes, pois se posicionam de modo a olhar fixamente para o intérprete, como se controlasse as palavras que estão saindo da boca de quem realiza a interpretação, demonstrando uma certa desconfiança no trabalho que está sendo realizado (Nogueira) (a) 178).
\end{abstract}

Nesse sentido, na cabine, qualquer suporte ou esclarecimento ocorre necessariamente entre os membros da equipe, equiparando 
na atuação os intérpretes de línguas de sinais na mesma posição dos intérpretes de línguas orais.

A possibilidade de uso dos recursos externos é um ponto interessante que foi levantado pelos participantes como vantagem. Obviamente, existe uma limitação para o acesso aos materiais, principalmente como intérpretes de língua de sinais que dependem da visão para acessar o discurso do palestrante. Há, porém, materiais externos de consulta rápida. Nas línguas orais, Pym sugere que dentro da cabine o intérprete pode ter acesso à memória eletrônica. Camargo (25) afirma que essa "memória eletrônica deverá apresentar uma configuração que permita o intérprete acessá-la, por questões lógicas de tempo e disponibilidade como, por exemplo, um glossário previamente organizado".

Nas experiências de intérpretes de língua de sinais, Nogueira (a) (119) relata sobre os cadernos de resumos - como conteúdos enviados pelos palestrantes - com o fim de disponibilizar material de apoio à interpretação, possibilitando o uso dentro da cabine. Esse apoio é descrito como produtivo, através da consulta para confirmar algum termo, ou informação disponibilizada no slide que é incorporada como escolha na interpretação. A norma técnica ISO 2023 (Directorate General for Interpretation web) indica que "a superfície de trabalho deverá ser suficientemente firme para adequar-se à escrita e manuseio de documentos", considerando assim que documentos textuais estiverem disponíveis para manuseio da equipe.

Os intérpretes participantes comentaram sobre o uso do celular ou computador, imaginamos que para língua de sinais, o uso desses recursos se dá pelo intérprete de apoio. No entanto, o celular pode se tornar um entrave na atenção para a equipe. É preciso um uso eficiente do recurso, para que não prejudique a atuação. Além disso, o uso do equipamento é outro ponto que poderia prejudicar a performance do intérprete. 


\section{Tabela 4}

O que prejudica a performance do intérprete

\section{Falas representativas}

Transmissão da P7- "O posicionamento da cabine pode ajudar ou prejudicar o trabalho do intérprete, pois imagem mesmo que ele esteja vendo o orador em língua de sinais no monitor, se não conseguir ver a apresentação de slides ou vídeos transmitidos durante a conferência seu trabalho será prejudicado."

P8- "Acredito que o mal-uso dos recursos tecnológicos pode atrapalhar a interpretação, por exemplo o microfone com os botões de ligar e desligar se trocados podem causar problemas, a sensibilidade do microfone em captar o som que emite o menor barulho, entre outros. Além disso é preciso de mais recursos do evento para bancar as cabines, o que o torna menos utilizado nos eventos."

P9- "O equipamento adaptado pode apresentar algumas complicações e interferir no processo interpretativo."

Fonte: elaborado pelo autor.

As respostas coletadas apresentam a relação entre equipe de intérpretes, equipe técnica de som, equipe responsável pelo equipamento e a equipe de gravação e vídeo - para as línguas de sinais - , fundamental para o andamento do trabalho. A normativa ISO 2603 (web), preconiza que "a cabine de controle de som deverá ser instalada próxima das cabines dos intérpretes para facilitar a comunicação entre eles e para que o operador tenha uma boa visão do auditório. $\mathrm{O}$ operador deverá ter acesso fácil, rápido e seguro às cabines, assim como ao auditório". Essa prescrição, tem relação direta com eventuais problemas serem rapidamente assistidos pela equipe técnica.

Conforme o questionário, algumas respostas dos participantes revelam a ocorrência de problemas de ordem técnica, P7 diz que "Em uma situação o monitor apagou por intermináveis minutos e tivemos que nos esforçar para enxergar o orador e seguir com a interpretação até que o problema foi resolvido" (Nogueira) (b) web). Nesse relato, ao narrar "intermináveis minutos", o participante expressa um sentimento de apreensão com o problema, e também, do esforço de continuar interpretando sem usar o recurso de monitor de vídeo da cabine, com a visão prejudicada pela distância do palco. P2 descreve uma situação parecida: "A conexão do monitor foi perdida! Mas conseguimos a tempo resolver, 
infelizmente fazendo a interpretação no auditório até resolver o problema!" (Nogueira) (b) web).

A experiência dos participantes do estudo demonstra que em algum momento o equipamento de vídeo pode falhar, sendo necessário uma intervenção rápida. Além disso, a dinâmica de gravação normalmente é alterada para eventos que são em línguas de sinais e estão sendo exibidos em telões e na cabine para a interpretação. Frequentemente, os técnicos de vídeo realizam cortes da imagem ou alteração das câmeras, que não são recomendadas em eventos em língua de sinais. Qualquer alteração no contínuo de transmissão da imagem pode prejudicar os intérpretes comprometendo a interpretação realizada, por perda de um sinal importante.

A ausência dos slides dos palestrantes no campo de visão dos intérpretes foi mencionada. O participante P6 narra acerca da dificuldade na leitura do Powerpoint. "O palestrante não disponibilizou o material e fazia muita referência e o retorno do vídeo era centralizado no palestrante. E não conseguia ver as referências citadas quando projetadas" (Nogueira (b) web). Os nomes de autores frequentemente são momentos de tensão e podem ser problemas interpretativos, registrar os nomes com antecedência é uma oportunidade de estudar, verificar a pronúncia, que auxilia muito na interpretação. Dessa forma, é importante que o palestrante esteja consciente do quanto a preparação da equipe qualifica o trabalho realizado.

Os intérpretes participantes, na pergunta sete, foram questionados sobre alguma dificuldade com o uso do equipamento técnico como por exemplo o microfone, botão de mute e televisão; em sua totalidade a resposta foi que não sentem dificuldade no manuseio. Alguns relataram que no primeiro momento houve impasse pela novidade, mas se adaptaram rapidamente. A ISO 2023 apresenta orientações específicas no item 8.1, indicando que na cabine "Deverá haver um console ou painel de controle para cada um dos intérpretes contendo controles individuais para ouvir e falar e os sinalizadores correspondentes, no caso de equipamentos portáteis, é permitido o uso de painéis de controle duplos" (Directorate General for Interpretation web, grifo nosso).

Cad. Trad., Florianópolis, v. 41, $\mathrm{n}^{0}$ esp. 2, p. 128-162, ago/dez, 2021. 156 
Esses sinalizadores e o controle individual são importantes para que não ocorra o que foi relatado por P8 “já aconteceu de minha dupla ter esquecido de ligar o microfone e o público ter perdido algumas informações por um tempo curto. Também acontece muito de a voz do apoio vazar no microfone e o público perceber" (Nogueira (b) web). Sobre esse ponto, o intérprete na função de apoio pode atentar se o microfone está ligado e, ao fazer alguma contribuição, evitando reproduzir ao público.

Os participantes também foram questionados sobre ações ou cuidados que podem contribuir com a interpretação simultânea na cabine na pergunta oito. Ao analisar as respostas, construímos um quadro que apresenta dez sugestões abordadas pelos participantes para um trabalho eficiente na cabine.

\section{Quadro 1}

Trabalho eficiente na cabine

1. Tela de tamanho adequado para visualizar o discurso da palestra e transmissão ininterrupta

2. Cabine espaçosa para movimentação dos braços e oferecimento de apoio em sinais.

3. Teste de áudio e vídeo antes do evento.

4. Equipe técnica qualificada e disponível durante todo o evento.

5. Cabine com isolamento acústico e iluminação adequada.

6. Localização da cabine em espaço tranquilo sem muitas movimentações.

7. Combinar formas de comunicação com o mestre de cerimônias.

8. Reuniões com a equipe de intérpretes para orientar sobre o funcionamento da cabine, acessórios e equipamentos.

9. Ter acesso na cabine também da transmissão dos slides dos palestrantes.

10. Local extra para estudo, encontro da equipe e palestrantes.

Fonte: elaborado pelo autor

Cad. Trad., Florianópolis, v. 41, $\mathrm{n}^{0}$ esp. 2, p. 128-162, ago/dez, 2021. 157 
Interessante notar que muitos desses itens são descritos na norma técnica ISO 2023, como requisitos estruturais e internos das cabines, equipamento de som e os painéis de controles. Um item que vale destacar é acerca da possibilidade de um espaço específico para a equipe, uma sala de intérpretes. No item 6.2 da norma técnica observamos a descrição sobre os itens dessa sala:

É aconselhável que haja uma sala de intérpretes próxima às cabines que poderá ser usada pelos intérpretes e operadores de som quando não estiverem trabalhando. Deverá ter luz natural e ser de tamanho suficiente para abrigar pelo menos o mesmo número de pessoas que o de postos de trabalho das cabines. Deverá ter uma entrada independente.

É aconselhável que esta sala seja dividida em duas áreas com as seguintes finalidades: a) área para estudo de documentos e colocação de avisos; b) área de relaxamento e de espera (Directorate General for Interpretation web).

Apesar de não ter uma relação direta com a cabine, esse local de estudo e descanso para a equipe, se torna um espaço de base durante o funcionamento do evento, contribuindo para as atividades realizadas na cabine posteriormente.

Ao final, os intérpretes foram questionados sobre o sentimento que tiveram ao atuar em equipe. Essa pergunta possibilitava aos participantes marcar mais de uma alternativa. 
Gráfico 2 - Sentimento dos intérpretes sobre o trabalho na cabine

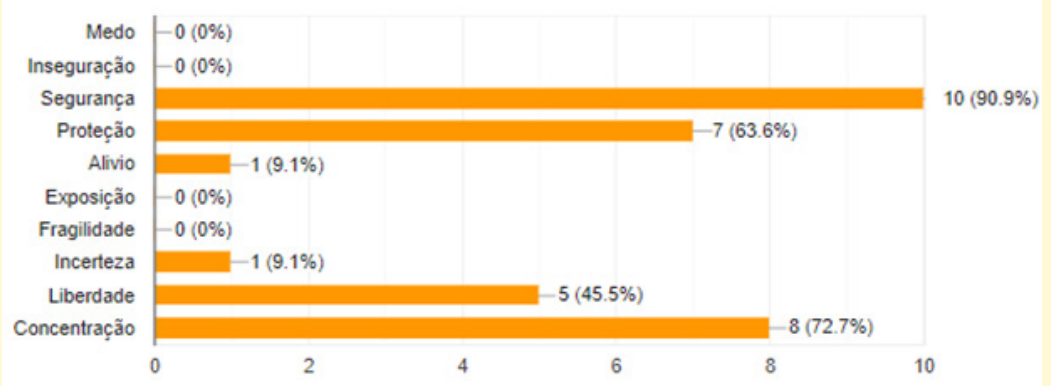

Fonte: arquivo do autor.

Podemos observar que sentimentos como: segurança, concentração, proteção e liberdade, destacam-se entre os mais elencados. Os sentimentos associados às representações mais negativas dessa experiência não foram selecionadas. Tais dados revelam o quanto os intérpretes se sentiram mais confiantes em cabine, em uma posição mais confortável, isto é, com menor tensão.

\section{Considerações finais}

Esse trabalho se propôs observar a experiência de intérpretes em conferências, atuando com Libras e Português na interpretação simultânea em cabine. Tematizamos aspectos relacionados à visão desses profissionais sobre a prática da interpretação simultânea realizada em cabine, visto que esse é um local novo para intérpretes que atuam com uma língua de sinais.

Quando eventos têm a língua de sinais como língua oficial, observamos algumas contribuições do uso da cabine como: (a) confiança maior dos intérpretes; (b) percepção de maior qualidade na interpretação com apoio e interação entre a equipe; (c) possibilidade de usar, de forma mais efetiva, recursos; (d) um local mais reser-

Cad. Trad., Florianópolis, v. 41, $\mathbf{n}^{0}$ esp. 2, p. 128-162, ago/dez, 2021.159 
vado para o trabalho com menos interferências de fatores externos auxiliando assim na concentração para o trabalho; (e) e, como já se mencionado acima, acreditamos que uma das principais vantagens é que a língua de sinais acaba tendo maior visibilidade, já que a cabine permite que ela seja realmente considerada língua oficial.

Além desses aspectos relacionados especificamente aos intérpretes, o público e os palestrantes estão em uma situação distinta quando a interpretação acontece na cabine. O público ouvinte-bilíngue e surdo estão na mesma condição, a relação que detalhamos de palestrante-intérprete se reconfigura. Uma vez que, os intérpretes devem procurar os palestrantes antes do evento para tirarem dúvidas e resolver questões que se apresentaram durante o estudo prévio, já que não poderão interagir durante a palestra, e o intérprete não poderá interromper o palestrante para questionar quando há incompreensão ou dúvida - fato que em alguns momentos ocorre quando o intérprete está no auditório.

Mais trabalhos podem ser realizados, contribuindo para a análise de outros aspectos da atuação na cabine em conferência, que está em desenvolvimento. A necessidade de cuidado e de atenção aos aspectos técnicos e tecnológicos são um elemento importante para a garantia da realização da interpretação. Por fim, vale salientar que o retorno auditivo é elemento fundamental para os intérpretes de línguas orais, enquanto o retorno visual - com a transmissão da fala do palestrante -, se torna peça chave para que os intérpretes consigam realizar o seu trabalho com qualidade.

A percepção dos intérpretes de Libras-Português sobre a prática da interpretação simultânea em cabine contribui para a popularização dessa prática nas interpretações e colabora com a profissionalização do serviço prestado em conferências. Registrar essa atividade e analisar os desafios enfrentados são formas de trazer subsídios para novos intérpretes e contratantes, suscitando reflexões sobre formas de aperfeiçoar o serviço prestado por toda a categoria.

Cad. Trad., Florianópolis, v. 41, $\mathbf{n}^{0}$ esp. 2, p. 128-162, ago/dez, 2021. 160 


\section{Referências}

Bowen. Margareta, et al. "Os intérpretes que fizeram história". Os Tradutores na história, organizado por Jean Delisle e Woodsworth, Judith. Tradução Sérgio Bath. 1 ed. São Paulo: Ática, 2003. p. 257-283. Tradução: Sérgio Bath.

Camargo, Patrícia Gimenez. "Competência em interpretação - um breve estudo da interpretação em língua B”. Tradterm, [s.1.], 23 (2014): 13-33. Universidade de São Paulo Sistema Integrado de Bibliotecas - SIBiUSP. Disponível em: < http:// www.revistas.usp.br/tradterm/article/viewFile/85506/88295>.

Cokely, Denis e Hawkins, Jennifer. "Interpreting in teams: A pilot study on requesting and offering support". Journal of Interpretion 2013: 49-93.

Directorate General for Interpretation. "ISO 2603; ISO 4043". European Comission. 2016. Web. 10 jun $2020<$ https://ec.europa.eu/info/sites/ info/files/technical-specifications-for-conference-rooms-with-simultaneousinterpreting_2020_en.pdf $>$.

Luciano, Anita Holm Thomsen. A Interpretação simultânea sob a ótica da lingüística aplicada. Campinas, SP: [s.n.], 2005.

Magalhães Junior, Ewandro. Sua majestade o intérprete: o fascinante mundo da interpretação simultânea. São Paulo: Parábola Editorial, 2007.

Nascimento, Vinicius. Nogueira. Tiago Coimbra. Interpretação de conferências: diferenças e semelhanças na atuação de intérpretes de línguas de sinais de línguas orais na cabine. 2017, VIII Congresso Internacional da ABRATES (Associação Brasileira de Tradutores e Intérpretes).

Nogueira. (a) Intérpretes de Libras-Português no contexto de conferência: uma descrição do trabalho em equipe e as formas de apoio na cabine. 2016. Universidade Federal de Santa Catarina - Programa de Pós-Graduação em Estudos da Tradução, Mestrado em Estudos da Tradução. Disponível em: https:// repositorio.ufsc.br/xmlui/bitstream/handle/123456789/167619/341090.pdf;jsessi onid $=62 \mathrm{ABE} 982 \mathrm{C} 56 \mathrm{EED} 690 \mathrm{~F} 994 \mathrm{DCBC} 138466 \mathrm{~A}$ ? sequence $=1$. 
Nogueira. (b) "Questionário online”. Google forms. Web.

Pagura, Reynaldo. (a) "A interpretação de conferências: interfaces com a tradução escrita e implicações para a formação de intérpretes e tradutores”. DELTA, 19 (2003): 209-236. Scielo. 18 jun. 2020. Disponível em: < http://www.scielo. $\mathrm{br} /$ scielo.php?script $=$ sci_arttext\&pid $=$ S0102-44502003000300013\&lng $=$ en\&nr $\mathrm{m}=$ iso $>$.

Pagura. (b) A Interpretação de Conferências no Brasil: História de sua Prática Profissional e a Formação de Intérpretes Brasileiros. 2010. Universidade de São Paulo - Faculdade de Filosofia, Letras e Ciências Humanas, Doutorado em Estudos da Tradução.

Pyn, Anthony. "On Omissions in Simultaneous Interpreting: Risk Analysis of a hidden effort". Efforts and Models in Interpreting and Translation Research: A tribute to Daniel Gile, organizado por Hansen e Chesterman, Amsterdam: John Benjamins Publishing, 2009, pp. 83-108.

Roditi, E. Interpretating: Its history in nutshell. Wasshigton, D.C., Georgetown University, National Resource Center for Translation and Interpretation Outreach Paper. 1982.

Russel, Debra. "Team Interpreting": Best Practices, AVLIC, 2011. Web. Jun $2020<$ http://www.avlic.ca/sites/default/files/docs/2011-07Team_Interpreting Best_Practices_Article-by_Debra_Russell.pdf $>$.

Shuttleworth, M; Cowie, M. Dictionary of translation studies. New York: Routledge, 2014.

Tiago Coimbra Nogueira. E-mail: ticoimbrails@gmail.com. https://orcid. org/0000-0003-1248-7357.

Cad. Trad., Florianópolis, v. 41, $\mathrm{n}^{0}$ esp. 2, p. 128-162, ago/dez, 2021. 162 